\title{
IPI Score 2
}

National Cancer Institute

\section{Source}

National Cancer Institute. IPI Score 2. NCI Thesaurus. Code C161647.

A score of 2 on the International Prognostic Index indicating that an individual has a lowintermediate risk of progression of non-Hodg kin lymphoma and a 5 year survival of $69 \%$. 